\title{
Sensor based Management Information System for Dumpers for Indian Mines
}

\author{
M S Tiwari, Manish Uttarwar
}

\begin{abstract}
Mining is the backbone of any industrial activity. Mother nature has bestowed India with good deposits of coal, iron ore, limestone, bauxite, manganese and chromite ores. Indian economy is one of the fastest growing economies in the world today. To fulfill 8-10 \% growth target, Indian mining industry has to increase its share from $2.4 \%$ to $6 \%$. (1)Such voluminous increments can be met only by employing big size heavy earth moving machines (HEMM)(2). Dumpers are the common choice in all types of mines for material movement. There are 4200 dumpers of various sizes being used in the different mines in India. The cost of dumpers varies from Rs 1.0 crore for 35 tons to Rs 24 crore for 240 tons version.( 3) The availability and utilization percentage of dumpers is low as compared to other HEMM. Hence there is a need for continuous monitoring of operational and machine parameters. Presently, only in large mines GPS based systems are being used to monitor such parameters. In small and medium mines monitoring is manual in nature. Manual method of data generation has its own limitations with respect to time and reliability. GPS based systems are not only costly but also requires qualified manpower to operate and maintain it. This calls for indigenous development of economical management information system (MIS) which could produce temper proof on line data. This research paper discusses one such management information system developed by the authors which is economical, easy to maintain and which produces reliable data.
\end{abstract}

Key Words : HEMM, Costly, MIS

Associate Professor, Department of Civil Engineering, Shri Ramdeobaba College of Engineering and Management, Nagpur

Professor, Rajiv Gandhi College of Engineering, Research and Technology, Chandrapur

\section{INTRODUCTION}

Mining is the backbone of any industrial activity. The industrial revolution in $20^{\text {th }}$ century in Europe and America were supported by power from coal. India is the third largest producer of coal and holds sixth largest coal deposits. Similarly we have good deposits of steel industry and base industry minerals. The Indian economy is expected to grow at plus $7 \%$ rate and hence mining companies in India are facing challenges of meeting demand. Bigger size heavy earth moving machineries can only solve the volume requirement. Dumpers are the common choice in all types of mines for material movement. There are 3200 dumpers of various sizes being used in the mines of CIL. Another 1000 dumpers are expected to be in use in iron ore, limestone and other mechanized mines in the country.(3)

Rear discharge dumpers are mostly used in Indian Mines. Present size ranges from 60 tons to 240 tons. CIL is planning to introduce $320-360$ tons dumpers in some of the mines.(7) The cost of dumpers varies from Rs 3.0 crore to Rs 24 crore depending upon the size. CIL had carried out an

Revised Manuscript Received on July 10, 2019.

M S Tiwari, India.

Dr Manish Uttarwar, India. internal study a few years ago which revealed that losses could be as high as Rs 50,000 if a 170-tonne truck remained idle for half an hour. The figure would be double if the truck has larger capacity say, 240 tons.(6) Dumpers in Indian mines have the low availability (67\%) and utilization(50\%) as standards set by CMPDIL. (5) Against this the data collected from Northern Coalfields Limited ( NCL) indicates that actual availability was $66 \%$ and utilization $36 \%$ only.(8) The idle time cost for for such costly fleet is really very high and hence it calls for continuous evaluation of all operational parameters of dumper.

Better capacity utilization of dumpers depends upon haul road conditions, preventive maintenance and spares management. Data related to idle time is required to be properly logged and analyzed. Normally it is manual in nature. Manual method of data generation has its own limitations with respect to time \& reliability. This calls for development of management information system (MIS) by using automatic gadgets which produces on line data which is temper proof. Another feature which is desired is that its installation and maintenance should be such that mine management should be able to do it. Unlike GPS, which requires specialized manpower to operate and maintain it.

\section{SYSTEMS AVAILABLE FOR MONITORING DUMPER PARAMETERS}

A standard dump truck is a truck chassis with a dump body mounted to the chassis. The bed is raised by a vertical hydraulic ram mounted under the front of the body, or a horizontal hydraulic ram and lever arrangement between the frame rails and the back of the bed is hinged at the back of the truck. The dumpers that are used in opencast mines have a rigid frame and conventional steering with drive at the rear wheel. Most large size haul trucks employ diesel-electric power trains, using the diesel engine to drive an $\mathrm{AC}$ alternator or DC generator that sends electric power to electric motors at each rear wheel.

\section{OITDS:}

OITDS stands for operator independent truck dispatch system. In every dumper GPS sensors are installed which continuously communicates with at least four satellites. The control room in the mine is able to see on screen location of the dumper and it can direct the dumper to such loading machine where the queuing time is minimum. Thus dumpers and shovels can be utilized to better level of utilization. Such systems are costly and require technically competent manpower to operate and maintain it.(9) 


\section{RESULTS \& DISCUSSIONS}

Radio frequency identification technology has been tried in some mines. The location of the dumper is obtained by putting a radio tag over it. On the haul road at specified interval radio frequency receivers are installed. When the dumper crosses one such post, the receiver of the post catches frequency emitted by radio tag fixed at the dumper. This data is transmitted to a nearby receiver which is normally towered mounted. The tower mounted antenna transmits the received data to a control room. Hence at control room location of every dumper is obtained at some interval of time. The data obtained in intermittent and can be easily tempered. (10)

\section{MONITORING PARAMETERS}

Dumpers are the life line of every opencast project in our country. Operational parameters like availability time of dumper, dumper loading time, loaded cycle time, unloaded cycle time, numbers of trips made, haul road condition etc. can present some useful decision making data. Loading time of a dumper can tell us about blast quality and shovel operator efficiency. From loaded/unloaded cycle time data parameters like optimum loading distance, dumper operator efficiency, fuel consumption, maintenance quality, haul road condition etc. can be evaluated or correlated. Monthly data can be used to generate reports like shift wise comparison, operator wise comparison, quality of haul road, maintenance cost verses haul road condition etc.

\section{ELECTRONICS SENSORS WHICH CAN BE USED TO GENERATE THE DATA}

Many electronic gadgets are available which can be used to generate the required data. Normally the data is generated in the form of signals /pulses. These signals/pulses are then converted into useful information. Information can be processed and can be presented in the form of managerial data.

Different types of sensors working on different principles can be used but mining conditions like high temperatures, vibrations, dust, etc. warrants use of rugged gadgets. This restricts the choice of sensors. In case of dumpers proximity sensors and distance measuring sensors have worked well. Micro controller based data storage and processing is a better option than using a computer because of dust, vibration and space restrictions. Small size carbon printers can be used to generate shift wise reports. Data can be stored for a period of a month and then the stored data can be transferred to a laptop by providing USB port.

\section{REQUIREMENTS OF INDIGENOUS TECHNOLOGY \& RESULTS}

Well the operational data we need can be generated by systems provided by OEMs, but the problem is of cost or possibility of tempering. GPS based systems are very costly and cannot be used only in large opencast mines. While designing the system we have to take into account the psychology of our miners, working systems and conditions. The system should be easily installable, usable and if it is removed at the time of major maintenance the mine officials should be able to reinstall it. Also the spares should be locally available and from the circuit diagrams given in the operating manual, mine officials should be able to maintain $\&$ calibrate them on their own. This eliminates costly AMC. The sensor based MIS system developed satisfies all these conditions.

\section{LOGIC USED FOR SENSOR BASED MIS SYSTEM FOR DUMPERS}

Three logics were developed in formulating this system. First logic was for recognizing the load as the dumper was being loaded and other logic was to recognize unloading of loaded dumper. Inductive D C type industrial proximity NPN sensors were used to recognize both load and unload conditions. The sensor starts sensing once the metallic part ( body of the dumper above the cabin) comes under its range. As the dumper is loaded by the loading machine the suspension of the dumpers are depressed by about $17-$ $18 \mathrm{~mm}$. The body of the dumper covers the cabin. There is a gap of about 18 inches between the two. One of the proximity sensors was installed over the cabin. In no load condition it was not able to recognize the metallic body of the dumper. As the dumper is loaded by the loading machine the suspensions are depressed and the distance between the body of the dumper and the cabin starts reducing. Normally for 60 ton dumper it is $2 \mathrm{~mm}$ per bucket load of loading machine. Normally to fully load a dumper the loading machine loads seven to eight bucket loads. The height of the sensor was so adjusted in the installation that it will be able to sense the body of the dumper after fourth load. The timer starts with this recognition and it indicates the load condition. The reduction in the height was also clubbed with time. Normally one loading cycle of the loading machine takes at least 45 seconds. Hence reduction of the height was noted down after 45 seconds only. If there is reduction in height due to some other parameter it gets eliminated automatically.

The second proximity sensor is mounted near the rear portion of the dumper close to the rotating pin of the body. A metallic strip is welded near the pin and it rotates along with the dumpers body when it is raised for unloading. When the dumpers body is in normal position the distance between the strip welded and the sensor is more than the recognizing distance of the sensor. Hence sensor is not able to recognize it. When the dumpers body is fully lifted for unloading, the welded strip comes close to the sensor and it is able to recognize metallic strip. If this condition is satisfied the system records it as unloading. The timer also records the time.

When above two conditions of load and unloading are satisfied the system records it as one load and stores it. The difference between load and unload time is the loaded trip time. Similarly when the next load condition is satisfied the difference between previous unload time and current load time is the empty trip time.

After loading the dumper travels towards the unloading point over the mine haul roads. As the haul roads are not smooth and has many undulations \& pot holes, the body of the dumper moves slightly in the vertical plane. Due to this 
movement the distance between the sensor and the body keeps on changing. In normal good haul road condition the body of the sensor should remain within the sensing range of the sensor. In bad haul road conditions many a time the body will be jerked upwards and it will go out of the sensing range of the sensor. Again in good patch it will come within sensing range. The number of times the body of the dumper is out of the sensing range can be used to give idea of the haul road condition.

The trip counts are displayed in the display screen and at the end of the shift the attached carbon printer prints the shift report which contains the dumper number, date, time and number of the trips. The display automatically rests with new shift timing. Keys are provided to put dumper number, shift times etc. The system has the memory base to record 100 shifts data. Data transfer to a laptop can be done through a USB port. The system can operate at 5/12 volts which is normally available at operator's cabin.

The wiring of the system is done in such a way that it does not affect routine maintenance. The system has been tested under drastic weather conditions like summer and rainy season and the performance of the sensors even with dust coating or grease has given satisfactory results. The maintenance team was able to replace back the sensors and calibrate them in positions on their own after major maintenance.

\section{CONCLUSION}

Indian mineral industry is facing challenges of meeting demands, increasing productivity and producing quality output at competitive price. We also have obligations towards contribution in Make in India Campaign. Indigenously developed gadgets are not only economic \& reliable but are easily acceptable as they take into account local conditions. Quality of decision making depends upon timely and reliable data. Use of such domestic technology can help us to improve quality of the decision making and to reduce idle time. Better utilization of extremely costly HEMM will improve productivity. Start ups in this sector are needed along with support by mining industry. A better interaction between mining industry and engineering institution is the need of the time.

\section{REFERENCES}

1. www. Make in india.com/ article/-/v/sector - survey- mining.

2. https://www.asianage.com/.../economy/.../7-8-per-centcontribution-of-mining-sector-

3. Data collected from field.

4. Technological developments for self reliance, Presentation of C N Durgseh, Bengaluru, Director ( M\&C), BEML.

5. Studies on availabilities and utilization of mining equipments - An overview, M E Michael Arputharaj, International Journal of Advanced Research in Engineering and Technology, Vol. 6, Issue 3, March 2015.

6. https://m.economictimes.com $>$ Tech $>$ software

7. https://www.thehindubusinessline.com/.../coal-india-planshuge- ending/artical 230917

8. Data collected from IR department of Northern Coalfields Limited.

9. https://www.slideshare.net/Achutanandan/oitds-60049009
10. Application of Radio Frequency identification( RFID )in Mining Industry, Mohd Khairul Nizam Mahmad etc, International Conference on Innovative Research 2016 - ICIR Euroinvent 2016 